\title{
Mapping and classification of crops using high resolution satellite image
}

\section{R. Jagadeeswaran*}

Department of Remote Sensing and GIS, Tamil Nadu Agricultural University, Coimbatore641003 (Tamil Nadu), India

\section{A. Poornima}

Department of Remote Sensing and GIS, Tamil Nadu Agricultural University, Coimbatore641003 (Tamil Nadu), India

\section{R. Kumaraperumal}

Department of Remote Sensing and GIS, Tamil Nadu Agricultural University, Coimbatore641003 (Tamil Nadu), India

${ }^{*}$ Corresponding author. E-mail: jagawaran@tnau.ac.in

\section{Abstract}

In the present study an attempt was made to perform land use land cover classification at Level-III in order to discriminate and map individual crops. IRS Resources at 2 LISS IV sensor imagery (5.0 m spatial resolution) of September 2014 was utilized for the study. A hybrid classification approach of unsupervised classification followed by supervised classification was adopted to identify and map the crop area in Kodumudi block, Erode district of Tamil Nadu. Signature evaluation was carried out to study the class separability and through cross tabulation and the accuracy was assessed by error matrix. The signature separability analysis to classify various land cover classes indicated that the class viz., waterbody, settlement, sandy area and fallow land were better and for vegetation subclasses viz., individual crops were poor, which means classification of individual crops was a challenge. The overall accuracy with three different algorithms varied from 56 to 65 per cent and this low accuracy was due to the problem in discriminating the tonal variation and spectral pattern of individual crops in the study area. Thus, classification of vegetation categories into individual crops using LISS IV data resulted in moderate classification accuracy in areas with multiple cropping.

Keywords: Classification accuracy, LISS IV satellite image, land use land cover, spectral based approach

\section{INTRODUCTION}

Land use refers to the type of utilization to which man has used the land for his daily activities whereas, Land cover refers to the cover by the physical material at the surface of the earth which includes grass, crops, trees, forest, built up area, bare ground, water, lakes, etc. (Jensen and Cowen, 1999). Land use / land cover map of an area is useful information for planning, management and monitoring of natural resources at various levels. Thus, discrimination of crops from other land cover classes and their acreage estimation is essential for in-season management as well as for policy planning. Remote Sensing integrated with Geographical Information System, provides an effective tool for analysis and management of land use land cover (LULC) at cadastral level. Accurately identifying crops using information derived from earth observation satellites can contribute to improved use of resources and aids in timely agricultural planning. Crop type identification and area

\section{Article Info}

DOI:10.31018/jans.v10i3.1710

Received: April 25, 2018

Revised: June 4, 2018

Accepted: June 13, 2018

\section{How to Cite}

Jagadeeswaran, R. et al. (2018). Mapping and classification of crops using high resolution satellite image. Journal of Applied and Natural Science, 10 (3): $818-825$ 
curacy of 90-94 per cent. Land Use Land Cover map generated from LISS-III and LISS-IV images using MAXLIK and MINPAR supervised classification methods resulted in an overall accuracy between 90 and 95 per cent (Kiran et al., 2014). Sahu et al. (2014) delineated landforms and analyzed Land Use Land Cover on basaltic terrain of central India using IRS-P6 LISS IV image and identified six land cover classes viz., single crop, double crop, orchard, land with and without scrub and degraded forest. Kumar and Arya (2014) made an attempt at level III Land Use Land Cover classification using IRS P-6 LISS-IV data at Cadastral level and reported that high resolution satellite data has the potential to provide accurate spatial and temporal information for preparing large scale land use/land cover map of a region. Literature review suggests use of LISS IV data for crop mapping but discrimination and area estimation of crops in a complex cropping environment remain a challenge. In Tamil Nadu cropping system in many districts are mixed and the area extent is small and there is a need to identify and map the area under different crops. The information on crop area at cadastral level would help to plan for better input management like seed, pesticides and fertilizers and also for policy makers. With this background knowledge the present investigation was carried out to prepare Land use / Land cover map from high resolution Resourcesat 2 - LISS IV data in a complex cropping environment in Erode district of Tamil Nadu.

\section{MATERIALS AND METHODS}

The study area was Kodumudi block (consisting of 10 revenue villages), Erode district of South India which lies between $11^{\circ} 10^{\prime} 25.91^{\prime \prime} \mathrm{N}, 77^{\circ} 49^{\prime} 5.67^{\prime \prime} \mathrm{E}$ and $11^{\circ} 5^{\prime} 1.04^{\prime \prime} \mathrm{N}, 77^{\circ} 52^{\prime} 37.24^{\prime \prime} \mathrm{E}$. The total area was 10,509 hectares and cultivated with multiple crops at different seasons under irrigated and rainfed conditions. The dominant land use was irrigated agriculture, grasslands and human settlements. The River Cauvery runs across the area stretches to a length of 6.4 kilometers which is the major source of irrigation. The multispectral orthorectified LISS-IV sensor imagery from Resourcesat-2 (Path/Row: 101/66) with a spatial resolution of $5.0 \mathrm{~m}$ acquired on September 11, 2014 was purchased from National Remote Sensing Centre (NRSC), Hyderabad, for the study. Reconnaissance survey was conducted in the study area followed by ground truth to identify various land cover features and relate them to their tonal variation on the satellite image. Ground truth verification was performed to match with satellite pass date (10 days later) in the study area. Latitude and Longitude values along with the present ground cover and details of previous crops were collected at about 185 locations covering the entire study area. The ground control points were selected considering type of farming viz., irrigated and rainfed and land cover types (agriculture, fallow, scrub, water body, settlement etc.) and their distribution.

Training samples and signature evaluation: The image was subjected to unsupervised classification to identify natural groupings of spectral pattern by clustering method (Lillesand et al., 2007). The training samples were collected from different clusters obtained from the above method to perform level II classification. To perform level III classification training samples were collected considering finer visible spectral variations (for example four classes under vegetation and three classes under fallow land). The training signatures were evaluated by signature separability and distance analysis (Swain and Davis, 1978). Signature separability is a statistical measure of the distance between two signatures and this can be calculated for any combination of bands as well as class pairs that is used in the classification and thus enables the ruling out of any bands/class pairs that are not useful in the result of the classification. The separability analysis was performed through Transformed Divergence method in ERDAS software. Using the training signatures collected for level II and level III classes, the image was classified by maximum likelihood classifier algorithm and land use land cover classes were generated. In order to verify whether the signatures collected for level II (course spectral pattern) agree with the level III (finer spectral pattern) a method called cross tabulation was performed.

Image classification: Land use/land cover classification (LULC) was performed on LISS IV image through pixel or spectral based approach. Spectral based classification algorithm utilizes spectral pattern associated with different land cover types having unique or narrow range of digital numbers (DN) for evaluation and to identify typical pattern (Lillesand et al., 2007). Classification was performed to identify different cover classes on the ground viz., vegetation, waterbody, scrubland, settlement and sandy area. The spectral based classification approach was performed by supervised classification techniques and the algorithms tried were maximum likelihood classifier, minimum distance to mean classifier and mahalanobis distance classifier in Erdas software. In supervised classification technique training signatures of various crops and other land cover classes were generated based on the ground truth data collected at various locations. The different classes were identified on the image by their tonal variation and also with the help of GPS value. The land use land cover classification system of NRSC (2006) was used to define the land cover themes. Vegetation, Settlement, Waterbody, Sandy area, and Fallow land are classified under Level II Classes and also an attempt was made to classify the vegetation 
into various crops under Level III classes viz., Cassava, Turmeric, Coconut and Sugarcane. The flowchart indicating the methodology for LULC mapping is presented in Fig.1.

Accuracy assessment: Classification accuracy was assessed to define how close the classification agreed with the training sample. Classification accuracy was performed by preparation of a classification error matrix. The class allocation of each pixel in classified image is compared with the corresponding class allocation on reference data to determine the classification accuracy. The pixels of agreement and disagreement are compiled in the form of an error matrix, where the rows and columns represent the number of LULC classes and the elements of matrix represent the number of pixels in the testing dataset (Lillesand et al., 2007). Field checks have been performed for ascertaining the classification accuracy. Error Matrix for accuracy assessment has been generated and finally the land use map and reports have been prepared. The accuracy measures, such as overall accuracy, producer's accuracy and user's accuracy were estimated from the error matrix (Congalton, 1991).

Kappa coefficient: Kappa coefficient, a method of classification accuracy is a measure of the proportional (or percentage) improvement by the classifier over a purely random assignment to classes (Richards, 1993). The kappa coefficient was estimated from the formula given below.

$$
\widehat{K}=\frac{N A-H}{\mathbb{N}^{2}-B}
$$

This is for an error matrix with same number of rows and columns $(r)$

where,

$A=$ the sum of $\mathbf{r}$ diagonal elements, which is the numerator in the computation of overall accuracy $B=$ sum of the $r$ products (row total $x$ column total)

$\mathrm{N}=$ the number of pixels in the error matrix (the sum of all $r$ individual cell values)

\section{RESULTS AND DISCUSSION}

Signature avaluation: The training signatures collected for level II (course spectral pattern) and level III (finer spectral pattern) were subjected to separability distance analysis using Transformed Divergence method. The classes identified at level II classification were riverine sand, land sand, settlement, waterbody, vegetation and fallow land. Transformed Divergence methods resulted in a best separability value of 2000 for the class pairs viz., riverine sand: waterbody and vegetation; settlement: waterbody and vegetation, land sand: waterbody, waterbody: vegetation and land sand: vegetation, whereas, the minimum value was 1778 (settlement: land sand) and average was 1967.

The data on signature separability analysis carried

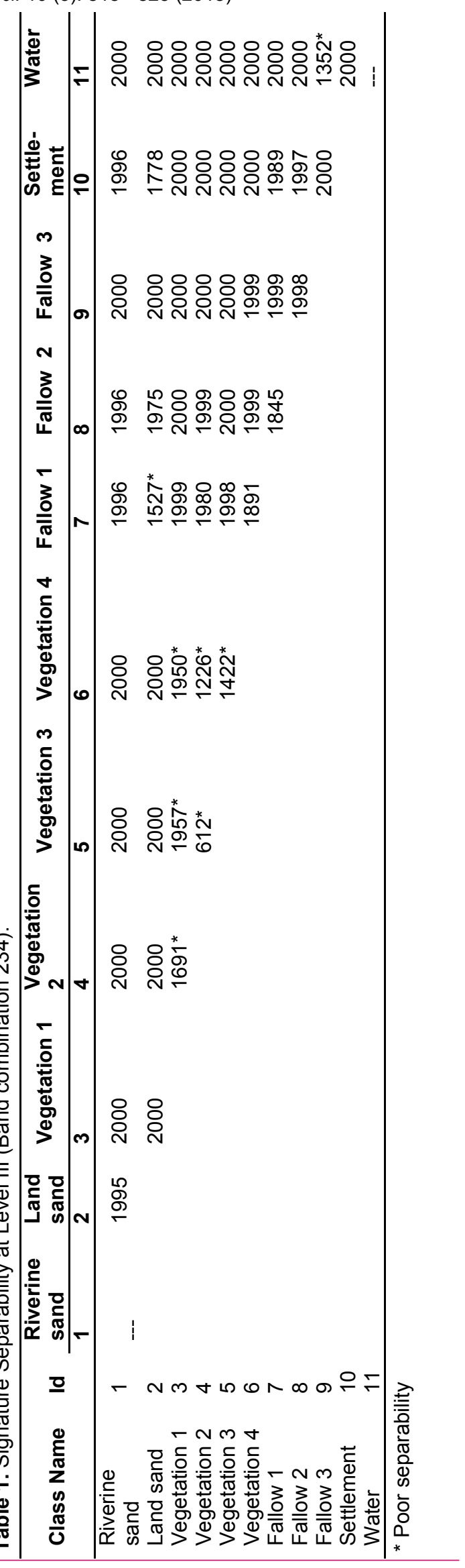


Jagadeeswaran, R. et al. / J. Appl. \& Nat. Sci. 10 (3): 818 - 825 (2018)

Table 2. Cross tabulation results of Level II and Level III classification.

\begin{tabular}{|c|c|c|c|c|c|c|c|c|}
\hline \multirow[b]{2}{*}{$\begin{array}{l}\text { Class Name } \\
\text { Level III }\end{array}$} & \multicolumn{7}{|c|}{ Level II } & \multirow[b]{2}{*}{ Total } \\
\hline & Vegetation & Fallow land & Waterbody & $\begin{array}{c}\text { Riverine } \\
\text { Sand }\end{array}$ & $\begin{array}{l}\text { Land } \\
\text { Sand }\end{array}$ & $\begin{array}{c}\text { Settle- } \\
\text { ment }\end{array}$ & $\begin{array}{l}\text { Unclas- } \\
\text { sified }\end{array}$ & \\
\hline Vegetation* & $\begin{array}{l}913551 \\
(98.45)^{\$}\end{array}$ & $\begin{array}{l}10011 \\
(1.08)\end{array}$ & 0 & 0 & 0 & $\begin{array}{l}4374 \\
(0.47)\end{array}$ & 0 & 927936 \\
\hline Fallow land" & $\begin{array}{c}100401 \\
(6.13)\end{array}$ & $\begin{array}{c}1422232 \\
(86.84)\end{array}$ & $\begin{array}{l}13679 \\
(0.84)\end{array}$ & $\begin{array}{l}4913 \\
(0.30)\end{array}$ & $\begin{array}{l}72319 \\
(4.42)\end{array}$ & $\begin{array}{l}24227 \\
(1.48)\end{array}$ & 0 & 1637771 \\
\hline Waterbody & 0 & $\begin{array}{c}85 \\
(0.10)\end{array}$ & $\begin{array}{l}83210 \\
(99.9)\end{array}$ & 0 & 0 & 0 & 0 & 83295 \\
\hline Riverine Sand & 0 & $\begin{array}{c}708 \\
(2.21)\end{array}$ & 0 & $\begin{array}{l}31287 \\
(97.79)\end{array}$ & 0 & 0 & 0 & 31995 \\
\hline Land Sand & 0 & $\begin{array}{l}12444 \\
(6.62)\end{array}$ & 0 & 0 & $\begin{array}{l}175629 \\
(93.38)\end{array}$ & 0 & 0 & 188073 \\
\hline Settlement & $\begin{array}{l}32514 \\
(2.46)\end{array}$ & $\begin{array}{l}71454 \\
(5.41)\end{array}$ & 0 & 0 & 0 & $\begin{array}{c}1216063 \\
(92.12)\end{array}$ & 0 & 1320031 \\
\hline Unclassified & 0 & 0 & 0 & 0 & 0 & 0 & $\begin{array}{l}14393 \\
(100)\end{array}$ & 14393 \\
\hline Total & 1046466 & 1516934 & 96889 & 36200 & 247948 & 1244664 & 14393 & 4203494 \\
\hline
\end{tabular}

*Vegetation = Vegetation 1+Vegetation 2+Vegetation 3+Vegetation 4; \# Fallow land = Fallow land 1+Fallow land 2+ Fallow land 3; \$ Figures in parenthesis indices percentage of correctly classified pixels under each category

Table 3. Area classified from different methods of classification at level III.

\begin{tabular}{llllll}
\hline S.N. & Class Name & $\begin{array}{l}\text { Maximum } \\
\text { Classifier (Area in ha) }\end{array}$ & $\begin{array}{l}\text { likelihood } \\
\text { (o Mean (Area in ha) }\end{array}$ & $\begin{array}{l}\text { Mahalanobis Dis- } \\
\text { tance (Area in ha) }\end{array}$ & Mean \\
\hline 1 & Turmeric & 869 & 1255 & 1196 & 1107 \\
2 & Sugarcane & 905 & 1037 & 430 & 791 \\
3 & Cassava & 166 & 127 & 176 & 156 \\
4 & Coconut & 838 & 474 & 395 & 569 \\
5 & Scrubland & 335 & 261 & 350 & 315 \\
6 & Fallow land & 3678 & 3505 & 4100 & 260 \\
7 & Waterbody & 233 & 323 & 223 & 209 \\
8 & Sandy area & 125 & 447 & 56 & 622 \\
9 & Settlement & 641 & 361 & 863 & 36 \\
10 & Unclassified & 36 & 36 & 36 & 7824 \\
Total & 7824 & 7824 & 2547 & \\
Total vegetation (1 to 5) & 3112 & 3153 & 390 & \\
Area & Transferred from \\
fallow land to vegetation & 598 & 916 & & \\
\hline
\end{tabular}

out for the training samples using Transformed Divergence method for Level III is presented in Table 1. The analysis produced similar results for best minimum and best average separability. The values ranged from 612 to 2000 with an average

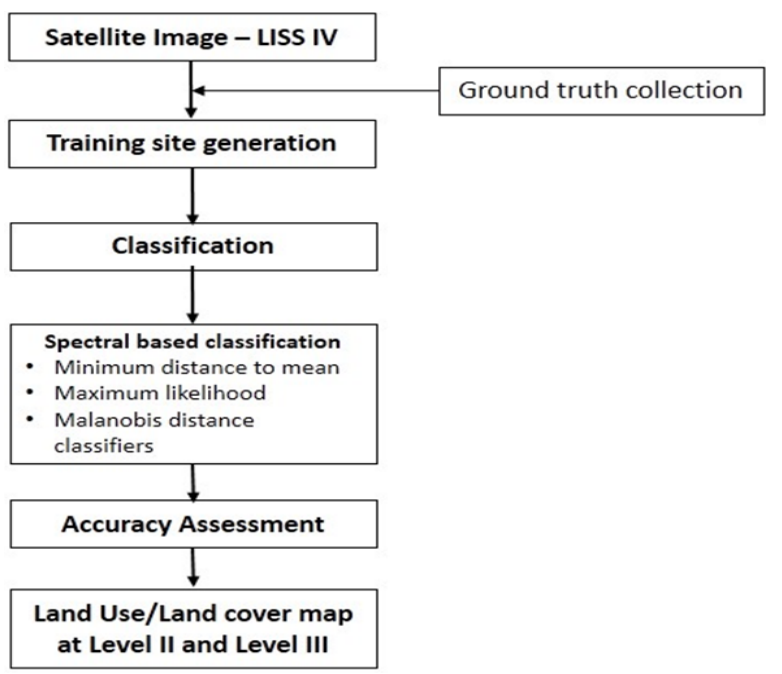

Fig.1. Methodology for land use/land cover mapping. of 1912 . The values were low $(<1700)$ for the pairs land sand: fallow land 1, vegetation 1: vegetation 2 , vegetation 2 : vegetation 3 and 4 , vegetation 3 : vegetation 4 and fallow land 3: waterbody (poor separability) and all other class pairs recorded values above 1700.The transformed divergence method yielded a reasonable separability distance between classes as evident from the data given in Table 1. According to Jensen (1996), the scale of the divergence values ranges from 0 to 2000 . As a general rule, if the value is greater than 1900 then the classes can be well separated. When it is between 1700 and 1900, the separation is fairly good and below 1700 indicates poor separability. In the present study the separability value obtained for level II classes with transformed divergence method ranged from 1778 to 2000 with an average of 1967 , which means at level II the classes were well separated. Whereas, the separability values for level III ranged from 612 to 2000 with an average of 1912. Except the class pairs Land sand: Fallow lands, Vegetation 1 versus 2, 3 and 4 and its combinations, all the other classes were well separated. 
Table 4. Error matrix resulting from classifying training set pixels at Level II.

\begin{tabular}{llllllll}
\hline \multirow{2}{*}{ S. N. } & \multirow{2}{*}{ Class Name } & \multicolumn{2}{l}{ Maximum likelihood } & \multicolumn{2}{l}{ Minimum Distance to Mean } & \multicolumn{2}{c}{ Mahalanobis Distance } \\
\cline { 3 - 7 } & & $\begin{array}{l}\text { Producer's } \\
\text { accuracy }\end{array}$ & $\begin{array}{l}\text { User's } \\
\text { accuracy }\end{array}$ & $\begin{array}{l}\text { Producer's } \\
\text { accuracy }\end{array}$ & $\begin{array}{l}\text { User's } \\
\text { racy }\end{array}$ & $\begin{array}{l}\text { accu- } \\
\text { Producer's } \\
\text { accuracy }\end{array}$ & $\begin{array}{l}\text { User's } \\
\text { accuracy }\end{array}$ \\
\hline 1 & Vegetation & 95 & 93 & 95 & 93 & 98 & 89 \\
2 & Fallow land & 78 & 80 & 79 & 74 & 72 & 89 \\
3 & Waterbody & 100 & 100 & 92 & 100 & 100 & 100 \\
4 & Sandy area & 91 & 100 & 53 & 90 & 100 & 80 \\
5 & Settlement & 90 & 90 & 94 & 75 & 82 & 90 \\
Overall accuracy (\%) & 91 & & 87 & & 89 & \\
\multicolumn{2}{l}{ Kappa Coefficient } & 0.86 & & 0.81 & & 0.84 & \\
\hline
\end{tabular}

Table 5. Error matrix resulting from classifying training set pixels for Level III.

\begin{tabular}{llllllll}
\hline \multirow{2}{*}{ SI. No. } & Class Name & \multicolumn{2}{l}{ Maximum likelihood } & $\begin{array}{l}\text { Minimum } \\
\text { Mean }\end{array}$ & Distance & to & \multicolumn{2}{c}{ Mahalanobis Distance } \\
\cline { 3 - 8 } & & $\begin{array}{l}\text { Producer's } \\
\text { accuracy }\end{array}$ & $\begin{array}{l}\text { User's } \\
\text { accuracy }\end{array}$ & $\begin{array}{l}\text { Producer's } \\
\text { accuracy }\end{array}$ & $\begin{array}{l}\text { User's } \\
\text { accuracy }\end{array}$ & $\begin{array}{l}\text { Producer's } \\
\text { accuracy }\end{array}$ & $\begin{array}{l}\text { User's } \\
\text { accuracy }\end{array}$ \\
\hline 1 & Turmeric & 25 & 40 & 17 & 40 & 22 & 60 \\
2 & Sugarcane & 27 & 40 & 36 & 40 & 27 & 30 \\
3 & Cassava & 71 & 50 & 78 & 50 & 71 & 50 \\
4 & Coconut & 63 & 45 & 52 & 45 & 65 & 26 \\
5 & Scrubland & 31 & 50 & 18 & 50 & 31 & 50 \\
6 & Fallow land & 78 & 80 & 79 & 80 & 72 & 86 \\
7 & Waterbody & 100 & 100 & 92 & 100 & 100 & 100 \\
8 & Sandy area & 90 & 100 & 53 & 100 & 100 & 80 \\
9 & Settlement & 90 & 90 & 94 & 90 & 82 & 90 \\
Overall accuracy (\%) & $\mathbf{6 5}$ & & $\mathbf{5 6}$ & & $\mathbf{6 2}$ & $\mathbf{0 . 5 6}$ \\
\multicolumn{2}{l}{ Kappa Coefficient } & $\mathbf{0 . 6 0}$ & & $\mathbf{0 . 5 0}$ & & \\
\hline
\end{tabular}

Cross tabulation of Land cover classes obtained from level II and III classification: Supervised classification of LISS IV image performed using the signature collected by considering course spectral pattern (level II) and finer spectral pattern (level III) were cross tabulated to check the percentage agreement of classes generated through two different methods. The cross tabulation result regarding number of pixels classified under each category is presented in Table 2. In order to have a meaningful comparison and classification efficiency the classes under the level III category viz., vegetation $1,2,3$ and 4 and fallow land 1, 2 and 3 were pooled under one name called vegetation and fallow land, respectively. The percentage of pixels classified correctly in each category is given in the parenthesis. It is evident from the Table 2 that 98.45 percentage of pixels were classified as vegetation and only 6.13 per cent pixels as fallow land and 2.46 per cent as settlement. Under fallow land 86.84 percentage of pixels were classified as fallow land and 6.6 per cent goes to Land sand, 5.4 per cent goes to settlement, 2.2 per cent as riverine sand and 1 per cent as vegetation. Waterbody classified as waterbody to the accuracy of 99.9 per cent. The other categories viz., Riverine sand, Land sand and Settlements were classified as the same category with an accuracy of $97.79,93.38$ and 92.12 percentage, respectively.

The idea of the cross tabulation was to know whether the training samples collected considering finer spectral pattern can be used for level III classification and are comparable with level II classes. The vegetation subclasses (vegetation 1 , 2, 3 and 4) and fallow land (fallow land 1, 2 and 3) were pooled for comparison. It is observed that the class vegetation classified as vegetation to the accuracy of 98.45 per cent. Thus, the training samples collected considering finer spectral pattern (varied levels of red tones) can be used as vegetation training samples. This is the case for other categories like fallow land, waterbody, sand and settlement also. Thus, the better accuracies suggest that this method of collection of training samples and classification are reliable.

Land use land cover classification: At level II classification five classes were identified viz., vegetation, fallow land, sandy area, settlement and waterbody. Among all categories fallow land occupy the highest area followed by vegetation. The maximum likelihood classifier classifies 4276 hectare (ha) under fallow land and 2512 ha under vegetation, 642 ha under settlement, 233 ha under waterbody and 125 ha under sandy area. Similar trend was observed with other two classification methods also however, the class viz., settlement and sandy area were not uniformly classified among three methods. The reason for this difference in the area obtained among three methods could be due to overlapping of tonal pattern (otherwise similar digital number in all the three layers) of settlement and sandy area. Ojigi (2006) reported that the classified area from maximum likelihood classifier was reliable and comparable with field data for a Land use land cover classification attempted using Landsat ETM+ data. The algorithms employed for classifying the satellite 
data at Level II were also used for Level III classification. The classified output (10 categories) from three methods is presented in Table 3. The area under turmeric was 869 ha (maximum likelihood), 1255 ha (minimum distance) and 1196 ha (mahalanobis distance method) with a mean of 1107 ha. The sugarcane area was 430 ha with mahalanobis method, 905 ha with maximum likelihood and 1037 ha with minimum distance method with a mean of 791 ha. Cassava recorded 166 ha (maximum likelihood), 127 ha (minimum distance) and 176 ha (mahalanobis method) with a mean of 156 ha. The coconut area was 838 ha (maximum likelihood), 474 ha (minimum distance) and 395 ha (mahalanobis method) with a mean of 569 ha. The area under fallow land was 3678 ha (maximum likelihood), 3505 ha (minimum distance) and 4100 ha (mahalanobis method) with a mean of 3761 ha. Scrubland area with maximum likelihood classifier was 335 ha, minimum distance to mean was 261 ha and mahalanobis distance method was 350 ha. The area under waterbody was 233 ha (maximum likelihood), 323 ha (minimum distance) to 229 ha (mahalanobis method) with a mean of 260 ha. The area under sand was 125 (maximum likelihood), 447 ha (minimum distance) and 56 ha (mahalanobis method) with a mean of 209 ha. Settlement recorded 863 ha from mahalanobis distance method, 361 ha from minimum distance and 641 ha from maximum likelihood method with a mean of 622 ha. About 36 ha found unclassified in all the three methods. The total area under vegetation was higher in level III than level II which was 598 ha with maximum likelihood, 916 ha in minimum distance to mean and 390 ha in mahalanobis distance method. That means these areas were transformed from fallow land to vegetation. The area under waterbody, sandy area and settlement remain more or less same as that of level II. Studies by different authors shows that pixel based methods applied to high resolution images results in inaccuracy of the classification due to salt and pepper effect (van de Voorde et al., 2004 and Sailesh Samanta et al., 2011). Since there is no official statistics available for current land use, the area obtained under each vegetation classes were unable to be confirmed. However, the area resulting from maximum likelihood classifier was considered accurate as reported by Murtaza and Romshoo (2014).

At level II the maximum likelihood classifier classified 2512 ha under vegetation whereas which was 3112 ha at level III. A difference of 600 ha was noticed between these two methods and this was the contribution from fallow land, i.e., a reduction of 598 ha was noticed under fallow land at level III. The area under fallow land at level II was 4276 ha and level III was 3678 ha. Whereas, the area under other classes remain unchanged. Similar trend was noticed with other two methods also.
The reason could be overlapping of signatures of training samples collected considering different crop type with fallow land. The fallow land in the study area covered with partial vegetation (weeds growth) could have contributed to signature overlap. The finding was in accordance with Dengsheng et al. (2010) where he reported misclassification errors due to spectral confusion among features at higher level.

Classification accuracy: Accuracy assessment is required for evaluating the quality of land cover classification results and also for identifying a suitable classification method. The elements used were overall accuracy, producer's accuracy, user's accuracy and kappa coefficient which are derived from error matrix. The accuracy of the classified output from level II classification was assessed by error matrix (also called confusion matrix or a contingency table). Error matrices compare on a category-by-category basis the relationship between known reference data (ground truth) and the corresponding results of an automated classification. Error matrix indicates how well a classification has categorized a set of pixels used in the training process. The error matrix result from the classification is presented in Table 4 and 5 .

The error matrix in Table 4 indicates an overall accuracy of 91 per cent, 87 per cent and 89 per cent for maximum likelihood classifier, minimum distance to mean classifier and mahalanobis distance method, respectively. The kappa co-efficient varied from 0.81 to 0.86 . The maximum likelihood classifier resulted in better producer as well as users accuracy followed by mahalanobis distance method. In all the methods, water body classified with 100 per cent accuracy followed by vegetation ( 89 to $98 \%$ ) and settlement (75 to $94 \%$ ). These findings are in accordance with Kiran et al. (2014), where they reported an overall accuracy of 90-95 per cent using LISS IV data. The reason could be the efficiency of maximum likelihood classifier algorithms than other methods. Patil et al. (2012) reported similar findings of higher accuracy with maximum likelihood classifier.

Accuracy assessment was also made for level III land use land cover classification on the LISS IV image involving three algorithms. The error matrix resulting from classifying training set pixels by maximum likelihood classification algorithm is presented in Table 5. There were ten land cover classes generated at level III. The overall accuracy obtained was 65 per cent with a kappa coefficient of 0.60 . The vegetation classes viz., turmeric, sugarcane and scrubland recorded very low accuracy percentage of 25, 27 and 31, respectively, whereas, the accuracy percentage with cassava and coconut were 71 and 63 , respectively. The classes such as fallow, settlement, sandy area and waterbody resulted in higher producer's accuracy 
of $78,90,90$ and 100 per cent, respectively. The user's accuracy which is an indicator of commission error ranged from 40 per cent to 100 per cent. The user's accuracy for vegetation was low for turmeric (40\%), sugarcane $(40 \%)$, coconut $(45 \%)$ and cassava (50\%) and high for waterbody, settlement, fallow land and sandy area $(80 \%$ to $100 \%)$.

The minimum distance to mean method produced an overall accuracy of 56 per cent and kappa coefficient of 0.50 (Table 5). The producer's accuracy varied from as low as 17 percent with turmeric to 94 per cent with settlement. Turmeric, sugarcane and land with scrub recorded very low accuracy percentage of 17,36 and 18 , respectively. Whereas, the accuracy percentage with cassava, coconut, fallow lands, settlement and water body were 78, 52, 79, 94 and 92 per cent, respectively. The user's accuracy for vegetation classes were low for turmeric $(40 \%)$, sugarcane $(40 \%)$, coconut $(45 \%)$ and cassava $(50 \%)$ and for classes viz., waterbody, settlement, fallow land and sandy area were higher $(80 \%$ to $100 \%)$.

The overall accuracy obtained with mahalanobis distance method was 62 per cent with a kappa coefficient of 0.55 . According to Landis and Koch (1977) a Kappa coefficient equal to 1 indicates perfect agreement and value close to zero indicates poor agreement. In the present study the kappa coefficient of 0.55 indicates moderate agreement (Table 5). The vegetation classes viz., turmeric, sugarcane and scrubland recorded very low accuracy percentage of 22, 27 and 31, respectively which indicates these land cover classes could not be classified effectively. Whereas, accuracy percentage with cassava and coconut were 71 per cent and 65 per cent, respectively indicates the classification approach followed in this study is effective in identifying and classifying the land cover classes viz., cassava and coconut. The settlement, sandy area and waterbody resulted in higher producer's accuracy of 82, 100 and 100 per cent, respectively this was possible with clear image tones. The user's accuracy for vegetation classes were low for turmeric $(60 \%)$, sugarcane $(30 \%)$, coconut $(26 \%)$ and cassava $(50 \%)$. The user's accuracy for waterbody, settlement, fallow land and sandy area were higher $(80 \%$ to $100 \%)$.

In the present study the overall accuracy was higher $(65 \%)$ with maximum likelihood classifier and lower $(56 \%)$ with minimum distance to mean and the mahalanobis distance method recorded 62 per cent. The producer's and user's accuracy were best $(100 \%)$ for waterbody followed by sandy area (90 to $100 \%$ ), settlement (around $90 \%$ ) and fallow land (78-80\%). The accuracy with vegetation categories was moderate in all the methods. The producer's accuracy ranged from 22-25 per cent (turmeric) to 63-65 per cent (coconut) in maximum likelihood method and mahalanobis distance method. Thus, classification of vegetation categories into individual crops using LISS IV data resulted in poor classification accuracy irrespective of types of algorithms used. This is presumably due to overlapping of spectral signatures which as reported by Gao and Mas (2008) and Lu et al. (2010). It was also reported that the choice of classification techniques can significantly influence the results from crop inventories, and the accuracy of classification algorithms varies according to landscape units of the study area (Dwivedi et al., 2004) and this is evident in the present study. Jaiswal and Verma (2013) reported a user's accuracy of 66 per cent for multiple crop and Ojigi (2006) obtained poor (21.8\%) to moderate $(68 \%)$ classification accuracy with the use of maximum likelihood and minimum distance method. Thus, the present investigation revealed that discrimination and mapping of individual crops grown in small patches using the LISS IV data resulted in moderate classification accuracy irrespective of type of algorithms used.

\section{Conclusion}

Land use land cover classification using LISS IV sensor data was effective for level II classification with an overall accuracy of 91 per cent with maximum likelihood classifier followed by mahalanobis distance $(89 \%)$ and minimum distance to mean classifier $(87 \%)$. The accuracy with level III classification was 65 per cent with maximum likelihood classifier, 62 per cent with mahalanobis distance and 56 per cent with minimum distance to mean classifier. The producer's and user's accuracy were 100 per cent for waterbody followed by sandy area (90 to 100\%), settlement (around $90 \%)$ and fallow land $(78-80 \%)$. However, the accuracy with vegetation categories was poor to moderate in all the methods, wherein producer's accuracy ranged from 22-25 per cent (turmeric) to 63-65 per cent (coconut) in maximum likelihood method and mahalanobis distance method. Thus, classification and mapping of individual crops in the present study using LISS IV data resulted in moderate classification accuracy irrespective of types of algorithms used.

\section{REFERENCES}

1. Congalton, R. (1991). A review of Assessing the Accuracy of Classifications of Remotely Sensed Data. Remote Sensing of Environment, 37, pp. 35-46.

2. Dengsheng Lu, Scott Hetrick, and Emilio Moran. (2010). Land Cover Classification in a Complex Urban-Rural Landscape with QuickBird Imagery. Photogrammetric Engineering \& Remote Sensing, 76 (10): 1159-1168.

3. Dwivedi, R.S., Sreenivas Kandrika and Ramana, K.V. (2004). Comparison of classifiers of remote-sensing data for land-use/land cover mapping. Current Science, 86 (2):328-335. 
4. Gao, Y. and Mas, J.F. (2008). A comparison of the performance of pixel-based and object-based classifications over images with various spatial resolutions. GEOBIA 2008-Pixels, Objects, Intelligence. GEOgraphic Object Based Image Analysis for the 21st Century, (G.J.Hay, T. Blaschke and D. Marceau, editors). University of Calgary, Alberta, Canada, ISPRS Vol. No. XXXVIII-4/C1. Archives ISSN No.:1682 -1777 , pp. 373.

5. Jaiswal, J.K. and Verma, N. (2013). Land Use Change Detection in Baragaon Block, Varanasi District Using Remote Sensing. International Journal of Engineering Science Invention. 2(7); 49-53.

6. Jensen, J.R. (1996). Introductory Digital Image Processing: A Remote Sensing Perspective, Prentice Hall, London.

7. Jensen, J.R. and Cowen, D.C. (1999). Remote Sensing of Urban/Suburban Infrastructure and SocioEconomic Attributes. Photogrammetric Engineering and Remote Sensing, 65, pp. 611-622.

8. Kiran, V.S.S., Srivastava, Y. K. and M. Jagannadha Rao. (2014). Utilization of Resourcesat LISS IV Data for Infrastructure Updation and Land Use / Land Cover Mapping - A Case Study from Simlipal Block, Bankura District, W. Bengal. International Journal of Advanced Remote Sensing and GIS, ISSN 2320-0243, 3 (1):592-597

9. Koppad, A.G. and Pavan Tikhile. (2012). Anthropogenic impact assessment on forestbiodiversity in coastal region of Uttara Kannada district using RS and GIS technique. The Ecoscan, Special issue, $1: 287-291$

10.Kumar, V. and Arya,V.S. (2014). Generation of Cadastral Level Information of a Micro-Watershed on Land Use / Land Cover through Geo-informatics. Journal of Environmental Science and Sustainability, 2(1):7-11

11.Landis, J.R. and Koch, G.G. (1977). A One-Way Components of Variance Model for Categorical Data. Biometrics, 33, 671-679

12.Lillesand, T.M., Kiefer, R.W. and Chipman, J.W. (2007). Remote Sensing and Image Interpretation. Fifth Edition, Wiley India, New Delhi

13.Lu, D. and Weng, Q. (2009). Extraction of urban impervious surface from an IKONOS image. International Journal ofRemote Sensing, 30 (5), 1297-1311.

14.Lu D, Hetrick S, and Moran E. (2010). Land cover classification in a complex urban-rural landscape with QuickBird imagery. Photogrammetric Engineering and Remote Sensing. 76:1159-1168

15.Mishra, A., Sateesh Karwariya, and Sandeep Goyal. (2012). Land use / Land cover Mapping of
Chhatarpur District, Madhya Pradesh, India Using Unsupervised Classification Technique. IOSR Journal of Engineering (IOSRJEN), 2 (10),pp. 51-56.

16.Murtaza, K.O. and Romshoo, S.A. (2014). Determining the suitability and accuracy of various statistical algorithms for satellite data classification. International Journal ofGeomatics and Geosciences, 4(4):585599.

17.NRSC. (2006). Manual of National Land Use Land Cover Mapping Using Multi-Temporal Satellite Data, Department of Space, Hyderabad.

18.Ojigi, L.M. (2006). Analysis of spatial variations of Abuja land use and land cover from image classification algorithms. In: Proceedings of the ISPRS Commission VII Mid-term Symposium 'Remote Sensing: From Pixels to Processes'. Enschede, Netherlands.

19.Patil, M.B, Desai, C.G and Umrikar, B.N. (2012). Image classification tool for land use / land cover analysis: A comparative study of maximum likelihood and minimum distance method. Intl. J. Geology, Earth and Environmental Sciences, 2(3): 189-196.

20.Rai, P.K., Sweta, Abhishek Mishra and Mohammad Onagh. (2011). Multi-seasonal IRS-1CLISS III Satellite Data for Change Detection Analysis and Accuracy Assessment: A Case Study. Journal of GIS Trends, 2 (1), pp. 13-19.

21.Richards, J.A. (1993). Remote Sensing Digital Image Analysis. Springer, Heidelberg,New York.

22.Sailesh Samanta, Babita Pal and Dilip Kumar Pal. (2011). Micro level thematic mapping of land use/ land cover using high spatial resolution satellite data (A case study on PNG UNITECH campus). International Journal ofAdvances in Science and Technology, 3(3), pp. 31-38.

23.Sahu, N.G.P. Obireddy, Nirmal Kumar, Nagaraju, M.S.S.,Rajeev Srivastava and Singh,S.K. (2014). Characterization of landforms and Land Use/ Land Cover in basaltic terrain using IRS-P6 LISS IV and Cartosat-1 DEM data: A Case Study. ICAR-National Bureau of Soil Survey and Land Use Planning, Nagpur, India. Agropedology, 24 (02), pp. 166-178.

24.Swain, P. H., and Davis, S. M. (1978). Remote Sensing: The Quantitative Approach. New York: McGraw Hill Book Company

25.Van de Voorde, T., De Genst,W., Canters, F., Stephenne,N., Wolff, E., and Binard,M. (2004). Extraction of land use/land cover- related information from very high resolution data in urban and suburban areas. Remote Sensing in Transition, Proceedings of the $23^{\text {rd }}$ Symposium of the European Association of Remote Sensing Laboratories, Mill Press, Rotterdam, pp. 237-244. 